This is the final peer-reviewed accepted manuscript of:

Pellicano, A., Lugli, L., Binkofski, F. et al. The unimanual handle-to-hand correspondence effect: evidence for a location coding account. Psychological Research 83, 1383-1399 (2019).

The final published version is available online at:

https://doi.org/10.1007/s00426-018-1009-4

Rights / License:

The terms and conditions for the reuse of this version of the manuscript are specified in the publishing policy. For all terms of use and more information see the publisher's website.

This item was downloaded from IRIS Università di Bologna (https://cris.unibo.it/)

When citing, please refer to the published version. 


\title{
The unimanual handle-to-hand correspondence effect: evidence for a location coding account
}

\author{
Antonello Pellicano ${ }^{1} \cdot$ Luisa Lugli $^{2} \cdot$ Ferdinand Binkofski $^{1} \cdot$ Sandro Rubichi $^{3,5} \cdot$ Cristina lani $^{4,5} \cdot$ Roberto Nicoletti $^{2}$
}

\begin{abstract}
The handle-to-hand correspondence effect refers to faster and more accurate responses when the responding hand is aligned with the graspable part of an object tool, compared to when they lay on opposite sides. We performed four behavioral experiments to investigate whether this effect depends on the activation of grasping affordances (affordance activation account) or is to be traced back to a Simon effect, resulting from the spatial coding of stimuli and responses and from their dimensional overlap (location coding account). We manipulated the availability of a response alternative by requiring participants to perform either a unimanual go/no-go task (absence of a response alternative) or a joint go/no-go task (available response alternative) and the type of response required (button-press or grasping response). We found no handle-to-hand correspondence effect in the individual go/no-go task either when a button-press (Experiment 1A) or a grasping (Experiment 2A) response was required, whereas a significant effect emerged in the joint go/no-go task, irrespective of response modality (Experiments1B and 2B). These results do not support the idea that complex motor affordances are activated for meaningful objects, but are rather consistent with the more parsimonious location coding account.
\end{abstract}

\section{Introduction}

Perception of objects or visual scenes can influence our motor behavior in an automatic, involuntary way. For instance, it has been widely shown that when pictures of objects (e.g., kitchen tools like cups or mugs) are presented in the center of the participants' visual field and with their handle jutting left- or rightward, responses are typically

Antonello Pellicano

apellicano@ukaachen.de

1 Division for Clinical and Cognitive Sciences, Department of Neurology Medical Faculty, RWTH Aachen University, Pauwelsstr. 17, 52074 Aachen, Germany

2 Department of Philosophy and Communication, University of Bologna, Via Azzo Gardino 23, 40122 Bologna, Italy

3 Department of Education and Human Sciences, University of Modena and Reggio Emilia, Viale Antonio Allegri, 9, 42121 Reggio Emilia, Italy

4 Department of Communication and Economics, University of Modena and Reggio Emilia, Viale Antonio Allegri, 9, 42121 Reggio Emilia, Italy

5 Center for Neuroscience and Neurotechnology, University of Modena and Reggio Emilia, Via Campi 287, 41125 Modena, Italy faster and more accurate when the orientation of the handle corresponds to the location of the response, compared to when there is no spatial correspondence between them (i.e., handle-to-hand correspondence effect, Tucker \& Ellis, 1998; see also Iani, Baroni, Pellicano, \& Nicoletti, 2011; Ottoboni, Iani, Tessari, \& Rubichi, 2013; Riggio et al., 2008; Iani, et al., 2018). This effect was employed to investigate the affordance activation hypothesis, according to which the perception of an object tool, beyond the extraction of mere perceptual features such as color, shape, size, and location orientation also activate actions which are consistent with its identity and its canonical use (e.g., Bub \& Masson, 2010; Goslin, Dixon, Fischer, Cangelosi, \& Ellis, 2012; Masson, Bub, \& Breuer, 2011; Pellicano, Iani, Borghi, Rubichi, \& Nicoletti, 2010b). According to this view, a perceived object activates appropriate grasping gestures whenever its identity and its functional meaning are recognized by the perceiver: whether these gestures will involve the left or the right hand will depend on the left- or rightward orientations of the object handle (variable affordances; see Borghi \& Riggio, 2015; Pellicano, Thill, Ziemke, \& Binkofski, 2011, see also Pellicano, Borghi, \& Binkofski, 2017a). As a result, responses to a graspable object become faster and more accurate when the responding hand is aligned with its left- or rightward jutting handle, compared to when it is not. 
More recently, the explanation of the handle-to-hand correspondence effect in terms of affordance activation has been questioned by a number of studies that support an alternative location coding account (Cho \& Proctor, 2010). According to this account, the graspable parts of the objects, as they protrude on one side, create visual asymmetries within the stimulus display that become perceptually salient to the observer. The location of these salient portions generates a left or right spatial code that may correspond or not with the response spatial code, thus generating a basic stimulus-response (S-R) spatial correspondence effect (Cho \& Proctor, 2011; 2013; Lien, Jardin, \& Proctor, 2013; Lien, Gray, Jardin, \& Proctor, 2014; Song, Chen, \& Proctor, 2014; see Proctor \& Miles, 2014 for a review). In other words, the handle-to-hand correspondence effect would correspond to an object-based Simon effect (Cho \& Proctor, 2010), that is, to the far preceding evidence that stimulus location (or orientation) can influence motor responses (e.g., button presses) even if it is task -irrelevant (see Simon, 1990; Pellicano, Iani, Rubichi, Ricciardelli, Borghi \& Nicoletti, 2010a; see Proctor \& Vu, 2006 for a review). Most recently, such an object-based Simon effect was also observed when visual asymmetries were provided by object parts different from the handle (e.g., a flashlight bulb, see Pellicano et al., 2010b; or the jutting spout of a teapot, see Cho \& Proctor, 2011; Pellicano, Koch, \& Binkofski, 2017b). Furthermore, Pellicano et al. (2017b) went beyond the original formulation of the location coding account. They provided evidence that the spatial coding of visual objects is not produced by mere structural asymmetries in their body, but depend on higherlevel iconic representations of depicted action directions (e.g., a plausible pouring action toward a second object).

The Simon effect is thought to depend on the dimensional overlap between stimulus and response sets (Kornblum, Hasbroucq, \& Osman, 1990), that is, when both stimulus and response alternatives share the same spatial codes (e.g., left and right). Within this condition, the stimulus determines the automatic activation of the ipsilateral response (e.g., stimulus on the right - automatic activation of the right response). When the required (correct) response and the automatic one are the same, the selection of the correct response is facilitated. On the contrary, when the required response and the automatic one differ, the automatic response must be inhibited to allow for the selection of the correct response; this will slow down the performance and make it more error prone.

To note, the dimensional overlap between the stimulus and response sets is a necessary condition for the emergence of the Simon effect. Indeed, when no dimensional overlap exists between stimulus and response sets, there is no automatic response activation and, as a consequence of this, no Simon effect can emerge. This is the case when a go/no-go task is employed in place of a choice-reaction task within a
Simon paradigm. In this variant, participants have only one response button at their disposal and are instructed to press it in response to only one of two possible stimuli. It has been shown that, even though the response button is physically located in the left or in the right hemispace of the participant, and corresponds to the stimulus location on half of the trials, no Simon effect is typically observed (e.g., Berlucchi, Crea, Di Stefano, \& Tassinari, 1977; Hommel, 1996; Lugli, Iani, Nicoletti, \& Rubichi, 2013, Lu \& Proctor, 1995; see also Ansorge \& Wühr, 2004 for a response-discrimination account of the Simon effect).

As a confirmation of the crucial role of S-R dimensional overlap, it has been observed that when a go/no-go Simon task is distributed between two participants (i.e., joint go/ no-go paradigm) the Simon effect turns significant (Sebanz, Knoblich, \& Prinz, 2003; 2005). In this paradigm, two participants sit alongside each other and operate one of two left and right buttons: one participant is instructed to press her/his assigned button to respond to one nonspatial feature of the stimulus, while the other participant has to press the other button to respond to the alternative nonspatial feature. Even though each participant performs her/his go/no-go Simon task, a significant Simon effect is typically observed (joint or social Simon effect). On the one hand, this finding has been taken as evidence that the two participants share a common representation of the full task set (i.e., co-representation account), which is assumed to be a dedicated, automatic social process (Sebanz, Bekkering, \& Knoblich, 2006; Sebanz \& Knoblich, 2009; Ferraro, Iani, Mariani, Milanese, \& Rubichi, 2011; Ferraro, Iani, Mariani, Nicoletti, Gallese, \& Rubichi, 2012; Milanese, Iani, \& Rubichi, 2010). On the other hand, a different interpretation has been proposed for the social element, that is, each participant forms representations of the co-actor and his actions exploiting them to shape and optimize his own task set (i.e., referential coding account-Dolk, Hommel, Prinz, \& Liepelt, 2013; Dolk et al., 2014; Dolk \& Prinz, 2016; Prinz, 2015; see Lugli, Iani, Milanese, Sebanz, \& Rubichi, 2015). Indeed, beyond the theoretical differences between these two approaches, it stays the crucial evidence for the purposes of the present study that the presence of a confederate participant and of his/her actions creates the preconditions for the (re)occurrence of the Simon effect as it (re-)establishes the spatial representation of response alternatives (left-right), and their overlap with the stimulus set (e.g., Ciardo, Lugli, Nicoletti, Rubichi, \& Iani, 2016; see also Dittrich, Rothe, \& Klauer, 2012, and Dittrich, Dolk, Rothe-Wulf, Klauer, \& Prinz, 2013 for an explanation of the joint Simon effect in terms of spatial-coding account).

Differently from the Simon effect, affordance effects should be independent from basic dimensional overlaps between stimuli and responses. Rather, affordances are thought to rely on more complex representations of stimulus 
manipulation. Evidence supporting this view is provided by studies showing affordance correspondence effects in unimanual go/no-go tasks. For instance, Tucker and Ellis (2001) investigated the effects of visual objects on motor responses during a categorization task. The responses consisted in unimanual precision or power grasps that could be compatible or incompatible with the size of observed graspable objects. They observed that size-grasp compatibility significantly speeded up participant response times. More recently, De Stefani et al. (2014) presented participants with coffee cups that could be randomly black and white, with the handle pointing to the right or to the left. The objects were presented at reachable and unreachable distances from the participant's body. When the cup was white, participants had to pantomime with their right hand an appropriate reach-grasp movement toward an end position that was $10 \mathrm{~cm}$ on the right of the cup, independently of handle orientation (i.e., go trials). When the cup was black, participants had to refrain from responding and wait for the next trial (i.e., no-go trials). A significant handle-to-hand correspondence effect was observed in the kinematic measures of the reach-grasp responses: when the cup was reachable and the handle was in the left side, noncorresponding with the grasping right hand, in which maximal finger aperture was enlarged compared to the corresponding handle-to-hand alignment (handle on the right), suggesting an adaptation of the gesture to the cup body size instead of the cup handle size.

However a recent study by Roest, Pecher, Naeije, and Zeelenberg (2016) provided evidence in part contrasting with an affordance activation account. They investigated a handle-to-hand correspondence effect (that they named alignment effect, p. 1665) through measures of lift-off time (i.e., the time from the onset of the stimulus to the start of the movement), and movement time (i.e., the time from the start of the movement to the grasping of the response device). Their results showed an alignment effect in a left-right choice-reaction task only for the lift-off time (Experiment 1). However, with a go/no-go task this effect reversed (Experiment 2), and became nonsignificant (Experiment 3 ) for both lift-off and movement times. They concluded that the alignment effects in the CRT of Experiment 1 was most likely due to task-induced competition, either between the left and right limb at the response level (Bub \& Masson, 2010) or between abstract spatial codes (e.g., Cho \& Proctor, 2010).

In the present study, we moved from the assumption that object grasping affordances should not be affected by changes in the experimental task that bring to the involvement of one hand as the only effector (i.e., no response alternatives are given), compared to when both the hands are involved (i.e., left/right response alternatives are given). Indeed, the motor repertoire that characterizes object manipulation, which is supposed to be automatically activated at stimulus perception, is not supposed to change when a unimanual go/no-go task is required instead of a bimanual choice-reaction task (a task commonly employed to investigate affordance effects). Furthermore, the upright orientation of graspable objects is more plausible to facilitate the activation of grasping affordances compared to upside-down orientation. For example, Riddoch, Edwards, Humphreys, West, and Heafield (1998) observed strong automatic grasp of objects handles in a patient with cortico-basal degeneration. When a cup was upright oriented, a grasping action was cued by the orientation of its handle in relation to the patient's preferred hand. However, when the cup was upside down, this grasp action decreased even though the handle orientation was the same as when the cup was upright (see also Rounis \& Humphreys, 2015).

In four experiments, we investigated the handle-to-hand correspondence effect when S-R dimensional overlap was removed from the experimental paradigm, as well as when it was reintroduced, and when two different response sets were employed.

In Experiment 1A, single participants performed a go/ no-go task requiring a right hand button-press response to picture stimuli of graspable objects with their handle located on the left or on the right side. In Experiment 1B, the same task was performed by paired participants performing a joint go/no-go task. In Experiments 2A and 2B, the same stimulus materials were employed, but a precision grip response was required to perform a single and joint go/no-go task, respectively. Furthermore, in Experiment $1 \mathrm{~A}$ and $2 \mathrm{~A}$, affordance activation was supported by assigning upright object stimuli to go trials, and upsidedown object stimuli to no-go trials.

The emergence of a handle-to-hand correspondence effect in Experiments 1A and 1B would support the idea that the effect is due to the activation of object affordances which emerge irrespective of the unimanual nature of the task, since they are independent of basic spatial representations of stimuli and responses and of their dimensional overlap. Conversely, the lack of a handle-to-hand correspondence effect in the individual go/no-go task (Experiment 1A) and its emergence in the joint go/no-go task (Experiment 1B) would support the location coding account for the handle-to-hand correspondence effect thus stating the crucial role of basic S-R dimensional overlap also within rich visual information. In Experiments $2 \mathrm{~A}$ and $2 \mathrm{~B}$, motor responses reproduced the actual grasping action required by the object stimuli. This manipulation was expected to increase the chances to activate consistent grasping affordances with respect to Experiment 1, thus providing better preconditions for the emergence of a handle-to-hand effect in both the individual go/no-go condition (Experiment 2A) and in the joint go/no-go condition (Experiment 2B). 


\section{Experiments $1 \mathrm{~A}$ and $1 \mathrm{~B}$}

\section{Materials and methods}

Participants 72 undergraduate students volunteered to participate in the study (56 from the University of Bologna and 16 from RWTH Aachen University). 24 students (19 females, 5 males; mean age 21.33 years; SD 1.65 years) participated in Experiment 1A, while 48 students (32 females, 16 males; mean age 23.74 years; SD 2.78 years) participated in Experiment 1B. In Experiment 1A participants performed a go/no-go task in which they were required to press a lateralized button with one hand to upright stimuli, while ignoring upside-down stimuli. In Experiment 1B, participants were randomly paired, and each pair performed a joint go/no-go task.

All participants were right-handed by self-report, reported normal or corrected-to-normal vision, and were naïve with regard to the experimental hypotheses. The present experiments and the following ones were approved by the local ethics committee and were conducted in accordance with the ethical standards laid down in the Declaration of Helsinki. All participants gave their oral informed consent to participate to the study.

Apparatus and stimuli The experiment was carried out in a dimly lit and noiseless room. Participants were seated facing a 17 " screen $(1024 \times 768$ resolution $)$ driven by a $700 \mathrm{MHz}$ PC. The eye distance from the screen was approximately $60 \mathrm{~cm}$. Stimulus presentation, response timing, and data collection were controlled by the E-Prime Professional v2.0 software (https://www.pstnet.com). A white fixation cross $\left(1.1^{\circ} \times 1.1^{\circ}\right.$ of visual angle $)$ and the target stimulus (covering a $5^{\circ} \times 5^{\circ}$ area) were presented on a black background at the center of the screen. Target stimuli were grayscale photographs (see Riggio et al., 2008) of four kitchen objects (a coffee pot, a milk jug, a teacup, and a beer mug) all sharing a jutting handle on one side, and centered on the base of their body. Each stimulus was displayed in four different configurations: two vertical orientations (upright vs. $180^{\circ}$ rotated/upside down) $\times$ two horizontal orientations (handle on the left vs. handle on the right, which is compatible with a left and a right hand grasp, respectively) for a total of 16 stimuli.

In Experiment 1A, the screen and the body of the participant were centered with respect to a vertical midline drawn on the table. One button box was placed on the table $10 \mathrm{~cm}$ on the left or the right of the vertical midline. Responses were emitted by pressing this button with the left or the right hand, respectively (Fig. 1, upper panel). In Experiment 1B, two participants sat side by side in front of the monitor and at the same distance from the table midline. Two button boxes were placed on the left and on
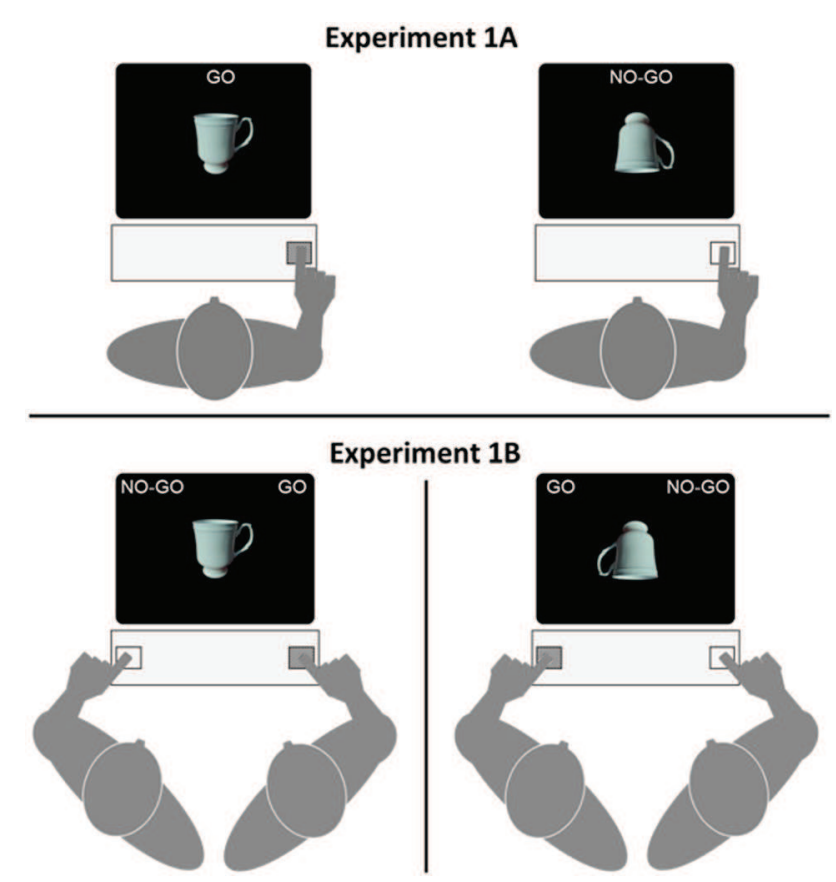

Fig. 1 Schematic representation of a handle-to-hand corresponding trial for the individual go/no-go Experiment 1A (upper panel), and the joint go/no-go Experiment 1B (bottom panel); both with button press responses and vertical discrimination task. In Experiment $1 \mathrm{~A}$, the responding hand and button was counterbalanced betweenparticipants. In Experiment 1B (paired participants) a go trial for one participant was a no-go trial for the other participant; the stimulusresponse mapping was counterbalanced-between-participants

the right side, at $10 \mathrm{~cm}$ from the midline. The participant on the left pressed the left button with the index finger of her/his left hand, whereas the participant on the right pressed the right button with the index finger of her/his right hand (Fig. 1, lower panel). In both the experiments for each participant, the non-responding hand was kept below the table.

Procedure At the beginning of each trial, the fixation cross was presented for $1000 \mathrm{~ms}$, followed by the target stimulus, which remained on the screen for a maximum of $1000 \mathrm{~ms}$ or until a response was emitted.

In Experiment 1A a go/no-go task was implemented: half the participants had the response button located on the left side and pressed it with the index finger of their left hand, whereas for the other half the button was located on the right side and pressed with the right index finger. Participants were instructed to press the response button to upright stimuli (i.e, go stimuli) and to refrain from responding when stimuli were upside down (i.e., no-go stimuli). In Experiment 1B, a joint go/no-go task was implemented: for half of the pairs, the participant on the left was instructed to press her/his response button only to upright stimuli, while the participant on the right was instructed to press her/his response button only 
to upside-down stimuli. For the other half of the pairs, response assignments were reversed.

In both the experiments, the orientation of the object's handle was task irrelevant and had to be ignored. Thus, the location of the responding hand of the single participant (Experiment 1A) and of the paired participants (Experiment 1B) could either spatially correspond with the horizontal orientation of the handle (i.e., corresponding trials) or not (i.e., non-corresponding trials). As soon as a correct response was emitted, the actual RT was displayed in the middle-bottom part of the screen for $1000 \mathrm{~ms}$. If a response to no-go stimuli or no response to go stimuli occurred, error and omission feedbacks were provided for 1000 ms together with a low pitch tone.

Both experiments comprised 12 training trials followed by 384 experimental trials divided into three blocks of 128 trials each. Stimuli were randomized within each block. Participants took short breaks between the blocks. The duration of the experiments was about $30 \mathrm{~min}$.

\section{Results and discussion}

In Experiment 1A, responses to no-go trials (i.e., errors) were $1.1 \%$ of the total trials while omitted responses to go trials were $0.3 \%$ of the total trials. Responses that were two standard deviations below $(0.7 \%)$ or above $(2.2 \%)$ each participant's overall mean were excluded from the analyses. In Experiment 1B, responses to no-go trials were $1.0 \%$ of the total trials, while omitted responses to go trials were $0.3 \%$ of the total trials. Responses that were two standard deviations below $(0.1 \%)$ or above $(1.3 \%)$ each participant's overall mean were excluded from the analyses.

First, we wanted to assess any potential difference in Experiment 1B between participants who responded to upright stimuli and those who responded to upside-down stimuli. To this end, correct RTs and error rates (i.e., responses to no-go trials-ERs) were submitted to two analyses of variance (ANOVAs) with Orientation (upright vs. upside-down stimuli) as between-subjects variable, and Correspondence (handle-to-hand corresponding vs. non-corresponding pairings) as within-subject variable. When necessary, post hoc comparisons were performed using paired samples $t$ tests and by correcting the $p$ value on the basis of the number of planned comparisons (Bonferroni correction).

For RTs, the main effect of Correspondence was significant $F(1,46)=32.965, p<.001, \eta_{p}^{2}=0.42$, with faster RTs in handle-to-hand corresponding relative to non-corresponding trials (400 vs. $411 \mathrm{~ms}$ ). The main effect of Orientation was significant, $F(1,46)=5.636, p=.022, \eta_{p}^{2}=0.11$, with slower responses to upside down $(420 \mathrm{~ms})$ than to upright (391 ms) stimuli. The interaction between the two factors did not reach significance, $F(1,46)<1$, meaning that the magnitude of the correspondence effect did not differ between upright and the upside-down orientation groups. For ERs, the main effect of Correspondence was significant, $F(1,46)=4.563, p=.038, \eta_{p}^{2}=0.09$, with a lower percentage of errors in handle-to-hand corresponding than in noncorresponding trials $(1.7$ vs. $2.3 \%)$. Neither the main effect of Orientation, $F(1,46)=1.344, p=.252, \eta_{p}^{2}=0.03$ (upright stimuli $=2.3 \%$, upside-down stimuli $=1.7 \%$ ), nor the Orientation $\times$ Correspondence interaction, $F(1,46)=2.031$, $p=.161, \eta_{p}^{2}=0.04$, reached significance (see Table 1).

Mean correct reaction times (RTs) for the two experiments were then submitted to mixed-design analyses of variance (ANOVA) with Experiment (Experiment 1A vs. Experiment $1 \mathrm{~B}$ ) as between-subjects variable, and Correspondence (handle-to-hand corresponding vs. non-corresponding trials) as within-subjects variable. Firstly, we compared responses to upright stimuli of all the participants in Experiment $1 \mathrm{~A}$ to responses of half the participants in Experiment $1 \mathrm{~B}$ who responded to upright stimuli. Secondly, we compared the same responses to upright stimuli in Experiment 1A to the responses of the other half the participants of Experiment 1B who responded to upside-down stimuli. All statistical tests were performed in SPSS (IBM, USA). When necessary, paired samples $t$ tests were performed as post hoc
Table 1 Mean response times (in milliseconds), and error rates (in percentage) as a function of object vertical Orientation (upright vs. upside down) and Correspondence (handle-to-hand corresponding vs. non-corresponding pairings)

\begin{tabular}{|c|c|c|c|c|c|c|c|c|c|c|c|c|}
\hline & \multicolumn{12}{|c|}{ Experiment } \\
\hline & \multirow{2}{*}{\multicolumn{2}{|c|}{$\frac{1 \mathrm{~A}}{\text { Upright }}$}} & \multicolumn{4}{|l|}{$1 \mathrm{~B}$} & \multirow{2}{*}{\multicolumn{2}{|c|}{$\frac{2 \mathrm{~A}}{\text { Upright }}$}} & \multicolumn{4}{|l|}{$2 \mathrm{~B}$} \\
\hline & & & \multicolumn{2}{|c|}{ Upright } & \multicolumn{2}{|c|}{$\begin{array}{l}\text { Upside } \\
\text { down }\end{array}$} & & & \multicolumn{2}{|c|}{ Upright } & \multicolumn{2}{|c|}{$\begin{array}{l}\text { Upside } \\
\text { down }\end{array}$} \\
\hline & RTs & ERs & RTs & ERs & RTs & ERs & RTs & ERs & RTs & ERs & RTs & ERs \\
\hline Handle-to-hand corresponding & 391 & 2.5 & 385 & 2.2 & 414 & 1.2 & 390 & 2 & 372 & 2.8 & 383 & 1.6 \\
\hline Handle-to-hand noncorresponding & 393 & 2.3 & 397 & 2.4 & 425 & 2.3 & 390 & 2.3 & 379 & 3.9 & 390 & 2.9 \\
\hline Correspondence effect & 2 & 0.2 & $12 *$ & 0.2 & $11^{*}$ & $1.1^{*}$ & 0 & 0.3 & $7 *$ & 1.1 & $7 *$ & 1.3 \\
\hline
\end{tabular}

The correspondence effect is computed as the difference in reaction times and error rates between noncorresponding and corresponding trials

Asterisks denote significant effects 
comparisons with Bonferroni corrected $p$ value. An opensource tool was used to compute Cohen's $d_{z}$ effect size for the $t$ tests (http://www.cognitiveflexibility.org/effectsize/).

Experiment $1 A$ vs. $1 B$ upright stimuli Mean RTs from Experiment 1A (392 ms) and Experiment 1B (391 ms) did not differ from each other, $F<1, \eta_{p}^{2}=0.0001$. The main effect of Correspondence was significant, with faster RTs in handle-to-hand corresponding (388 $\mathrm{ms}$ ) than in handle-tohand non-corresponding $(395 \mathrm{~ms})$ trials, $F(1,46)=11.620$, $p=.0014, \eta_{p}^{2}=0.20$. The interaction between Experiment and Correspondence was also significant, $F(1,46)=6.451$ $p=.015, \eta_{p}^{2}=0.12$. Paired-sample $t$ tests showed no significant handle-to-hand correspondence effect in Experiment $1 \mathrm{~A}$ (391 vs. $393 \mathrm{~ms}$ ), $t(23)=0.758, p=.456, d_{z}=0.16$, and a significant effect (i.e., with upright stimuli) in Experiment $1 \mathrm{~B}$ (385 vs. $397 \mathrm{~ms}), t(23)=3.630, p=.0014, d_{z}=$ 0.74, (Bonferroni-corrected $p$ level $=0.025$ ) (see Table 1;
Fig. 2 upper panel). For ERs no source of significance was observed, $F_{\mathrm{S}}(1,46)<1$.

Experiment 1A-upright vs. Experiment 1B-upside-down stimuli The main effect of Experiment was not significant (Experiment $1 \mathrm{~A}=392 \mathrm{~ms}$ vs. Experiment $1 \mathrm{~B}=420 \mathrm{~ms}$ ), $F(1,46)=3.459, p=.069, \eta_{p}^{2}=0.07$. The main effect of Correspondence was significant, with faster RTs in handleto-hand corresponding (403 ms) than in handle-to-hand noncorresponding (409 ms) trials, $F(1,46)=15.763, p<.001$, $\eta_{p}^{2}=0.26$. The interaction between Experiment and Correspondence was also significant, $F(1,46)=8.573 p=.005$, $\eta_{p}^{2}=0.16$. Paired-sample $t$ tests showed that the effect of Correspondence was significant in Experiment 1B (i.e., upside-down stimuli only: 414 vs. $425 \mathrm{~ms}), t(23)=4.749$, $p<.001, d_{z}=0.99$, compared to the above displayed nonsignificant effect in Experiment 1A (Bonferroni-corrected $p$ level $=0.025)$ (see Table 1; Fig. 2 upper panel). For ERs, the
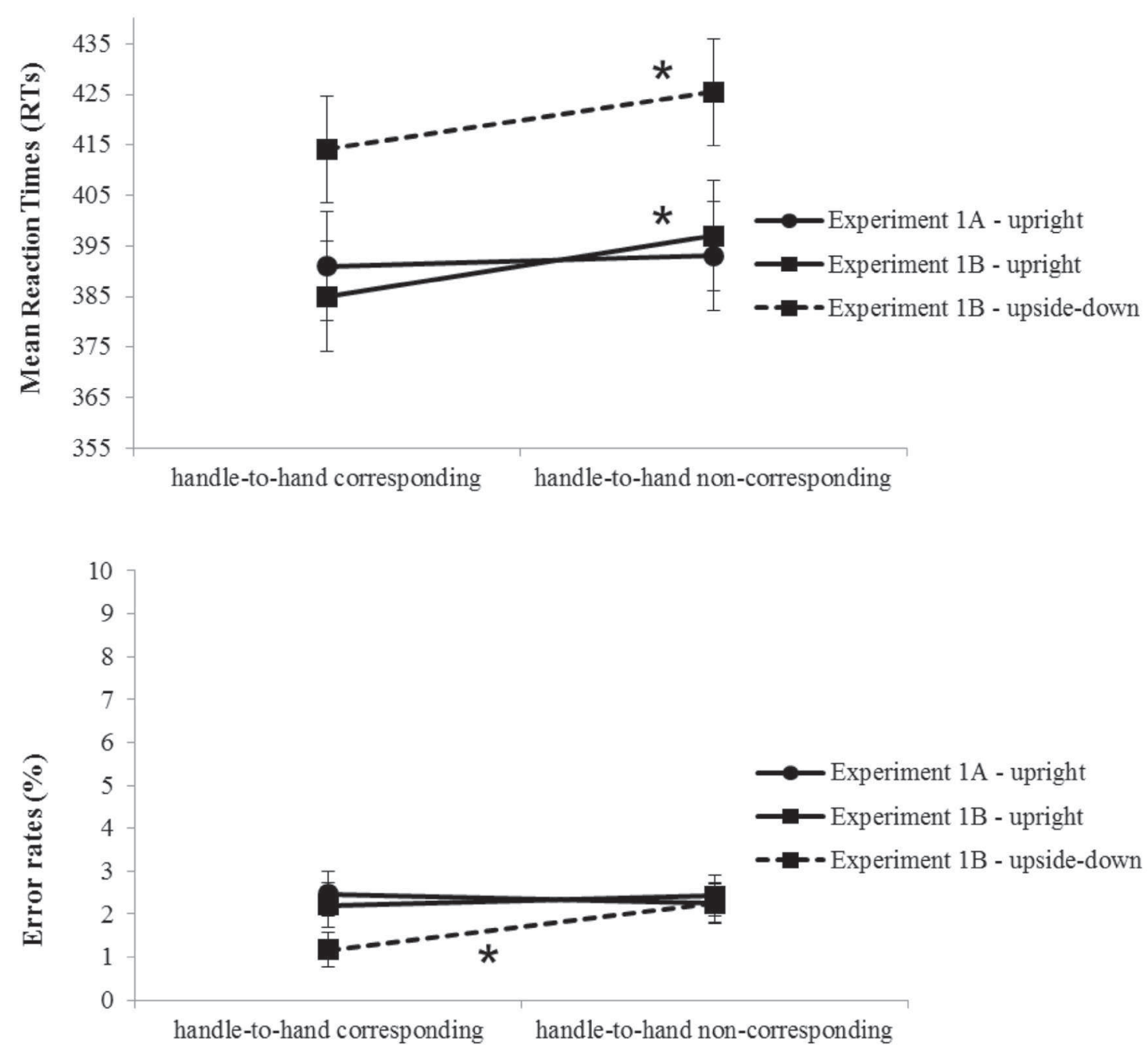

Fig. 2 Mean reaction times (RTs) in milliseconds, and error rates (ERs) in percentage as a function of Correspondence (handle-to-hand corresponding vs. non-corresponding trials) for Experiments $1 \mathrm{~A}$ and
1B. Asterisks denote significant differences. Bars represent standard errors of the mean 
main effects of Correspondence was not significant $(1.8 \%$ vs. $2.3 \%), F(1,46)=2.439 p=.125, \eta_{p}^{2}=0.05$. The main effect of Experiment was not significant too (Experiment $1 \mathrm{~A}=2.4 \%$ vs. Experiment $1 \mathrm{~B}=1.7 \%), F(1,46)=1.538$ $p=0.221, \eta_{p}^{2}=.03$; however, the Correspondence $\times$ Experiment interaction was significant, $F(1,46)=5.496 p=.023$, $\eta_{p}^{2}=0.11$. The effect of Correspondence was significant in Experiment 1B (i.e., upside-down stimuli only: 1.2 vs. $2.3 \%), t(23)=2.436, p=.023, d_{z}=0.52$, but not in Experiment $1 \mathrm{~A}(2.5$ vs. $2.3 \%), t(23)=0.655, p=.519, d_{z}=0.14$ (Bonferroni-corrected $p$ level $=0.025$ ) (see Table 1; Fig. 2 bottom panel).

The results of Experiments $1 \mathrm{~A}$ and $1 \mathrm{~B}$ speak against the affordance activation account. Indeed, according to this view the perceptual and motor meaningfulness of an object stimulus should not vary between a unimanual go/no-go task and a bimanual two-choice task. In other terms, the motor repertoire that characterizes object manipulation, including the appropriate hand, is not supposed to vary as a function of the available response set. In both the task situations, and peculiarly with objects presented in their upright canonical orientation, grasping affordances should be activated since participants' task requires access to the object's identity. Contrary to these predictions, no significant handle-tohand correspondence effect was observed in the individual go/no-go task of Experiment 1A, while a significant effect emerged in the joint go/no-go task of Experiment 1B. The results of Experiment 1A replicated those observed for go/ no-go versions of the Simon task employing simple, lateralized color stimuli and one response physically lateralized with respect to the body midline (Ansorge \& Wühr, 2004; Lugli et al., 2013), while the results of Experiment 1B replicated those of previous studies using joint go/no-go tasks (e.g., Ferraro et al., 2012; Sebanz \& Knoblich, 2009). The within-experiment analysis of Experiment $1 \mathrm{~B}$ clarified that the vertical orientation of the object stimuli had no influence on the correspondence effect observed in the joint go/no-go tasks. Even if the responses to upside-down stimuli resulted significantly slower than responses to upright stimuli, this did not affect the size of the correspondence effect as indicated by the nonsignificant interactions between Orientation and Correspondence in both the joint go/no-go experiments. This made the following between-experiments results even clearer, as the presence of a correspondence effect in the joint tasks and its absence in the individual ones could only be attributed to task differences. Taken together, the results are consistent with the alternative location coding account (Cho \& Proctor, 2010), according to which the handle-to-hand correspondence effect is a Simon-like effect that depends on the overlap between stimuli and responses abstract spatial codes (Kornblum et al., 1990). Thus, as for the individual go/no-go Simon task, the structure of the response set of Experiment 1A required a decision between the two options of pushing or not the response button. However, as these two options were not spatially distinct, spatial response codes were not created so that no S-R dimensional overlap was possible and, as a consequence, no correspondence effect was observed (see the response discrimination account of the Simon effect, Wühr \& Ansorge, 2007; Wühr et al., 2008). Differently, in the joint go/no-go task used in Experiment 1B, a Simon-like effect was re-instated because, due to either to co-representation of the task set (e.g., Sebanz et al., 2006), or the shaping of individual task set on the basis of the co-actor actions (i.e., referential coding account, Dolk \& Prinz, 2016; Prinz, 2015), two response alternatives were available and overlapped with the stimulus locations.

\section{Experiments $2 \mathrm{~A}$ and $2 \mathrm{~B}$}

In Experiments $1 \mathrm{~A}$ and 1B, responses were key presses. As suggested by Bub and Masson (2010; see also Bub, Masson, \& Kumar, 2018), handle-to-hand correspondence effects emerging when left-right key-press responses are required may stem from spatial coding. Indeed, motor affordances are more likely to emerge when responses are reach-and-grasp actions. Given these considerations, in Experiment 2A participants performed a go/no-go task executing a lateralized precision grasp with one hand. We hypothesized that the execution of object-appropriate grasping responses would create the conditions for the activation of motor affordances and, as a consequence of this, for the emergence of a significant handle-to-hand correspondence effect in the unimanual go/no-go task. It is plausible that stronger affordance effects would emerge when the required action more closely resembles the one afforded by the stimulus (e.g., Couth, Gowen, \& Poliakoff, 2014; Iani et al., 2011). For instance, Fagioli, Hommel, and Schubotz (2007) provided evidence that the processing of object shape was favored when grasping responses were employed, whereas location information was privileged with reaching responses. More specifically, Pavese and Buxbaum (2002) demonstrated that a distracting affording stimulus slowed RTs for reaching and grasping responses more than for a button-press response. Similarly, Bub and Masson (2010) showed that a reach and grasp action reliably yielded compatibility effects, whereas no such effects were found for a button-press response.

In Experiment 2B,paired participants performed a joint go/no-go task in which each participant was required to respond to either upright or upside-down stimuli by emitting a precision grasp response. The aim of the experiment was to assess whether, as occurred in Experiment 1B, the use of a joint go/no-go paradigm allows for the emergence of the handle-to-hand correspondence effect. 


\section{Materials and methods}

Participants 72 undergraduate students from the University of Bologna and from RWTH Aachen University volunteered to participate in the study. 24 students (16 females, 8 males; mean age 23.0 years; SD 3.10) took part in Experiment 2A and performed a go/no-go task. 48 students took part in Experiment 2B (34 females, 14 males; mean age 22.52 years; SD 3.92 years); they were randomly paired and each pair performed a joint go/no-go task. All reported normal or corrected-to-normal vision were right-handed by selfreport and were naïve with regard to the hypotheses of the experiment.

Apparatus, stimuli and procedure In Experiment 2A, apparatus, stimuli and procedure were the same as in Experiment $1 \mathrm{~A}$, except for the fact that responses mimicking a fine grasp movement (very similar to the one proper for the depicted objects) were employed instead of button presses. Half the participants responded with the right hand and the other half with the left hand. They placed their elbow on the table at approximately $25 \mathrm{~cm}$ from the screen while holding a $15 \mathrm{~mm}$-thick button box between the thumb and the index finger. The button box with the two grasping fingers was held at $1 \mathrm{~cm}$ distance from the screen surface, on its vertical midline, and $10 \mathrm{~cm}$ laterally to its center (i.e., on the left or on the right side of the stimulus presentation area for participants responding with the left or the right hand, respectively). Indeed, this posture allowed them to mimic a precision grip consistent with the size and the shape of the objects handles (see the schematic representation in Fig. 3, upper panel).

In Experiment 2B, participants sat side by side in front of the monitor, both holding one button box with the same posture and the same grasp movements as in Experiment 2A. Specifically, the participant on the left performed the grasping response with her/his left hand, whereas the participant on the right performed it with her/his right hand (Fig. 3, bottom panel). In both the experiments, the responding hands and their grasping movement could be compatible with the orientation of the objects' handle (i.e., corresponding trials) or incompatible with it (i.e., non-corresponding trials; in which the grasping gesture was produced but with the handle on the opposite side).

\section{Results and discussion}

In Experiment 2A, responses to no-go trials (i.e., errors) were $1.1 \%$ of the total trials while omitted responses to go trials were $0.3 \%$. Responses that were 2 standard deviations below $(0.1 \%)$ or above $(2.2 \%)$ each participant's overall mean were excluded from the analyses. In Experiment 2B, responses to no-go trials were $1.4 \%$ of the total trials while omitted responses to go trials were $0.1 \%$. Responses that
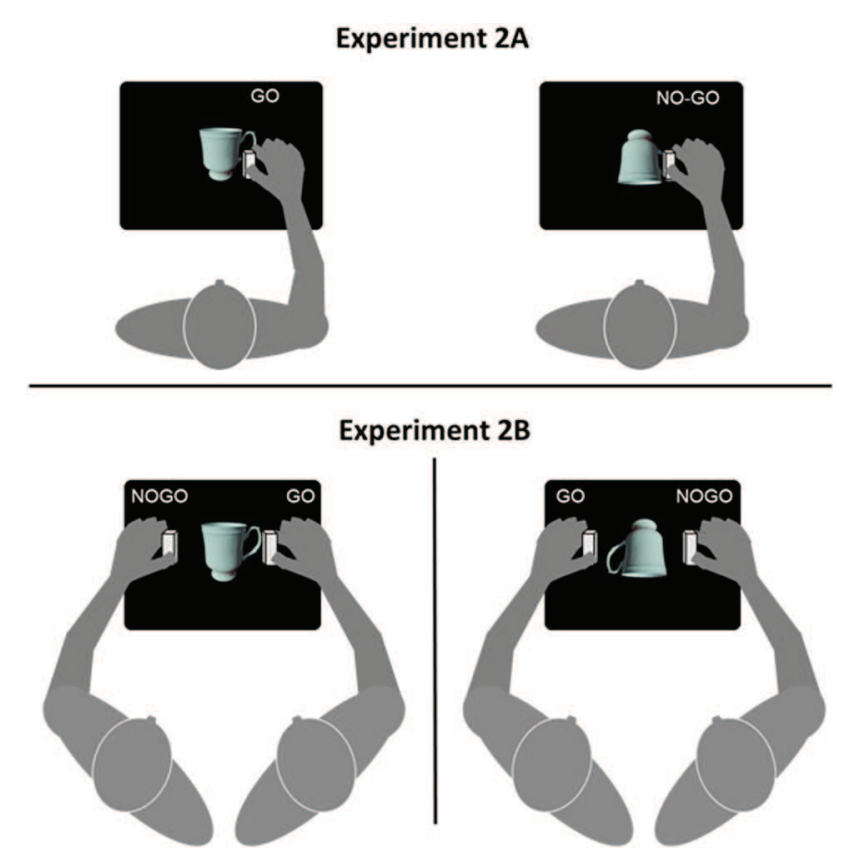

Fig. 3 Schematic representation of Experiment 2A and Experiment $2 \mathrm{~B}$, both with precision grasp responses and vertical discrimination task. Handle-to-hand correspondence is represented for each correct response. Upper panel: Individual go/no-go task performed in Experiment 2A; the responding hand and button was counterbalanced between-participants. Lower panel: joint go/no-go task performed in Experiment 2B; stimulus-response mapping was counterbalanced between-participants

were 2 standard deviations below $(0.2 \%)$ or above $(2 \%)$ each participant's overall mean were excluded from the analyses.

The first analysis was performed on the data of Experiment $2 \mathrm{~B}$ to control for possible effects of object vertical orientation between the groups. Correct RTs and ERs were submitted to separate ANOVAs with Orientation (upright vs. upside-down stimuli) as between-subjects variable, and Correspondence (handle-to-hand corresponding vs. noncorresponding pairings) as within-subject variable. When necessary, paired samples $t$ tests were performed as post hoc comparisons with Bonferroni-corrected $p$ value.

For the RTs, the main effect of Orientation did not reach significance, $F(1,46)=<1, p=.381, \eta_{p}^{2}=0.02$ (375 and $386 \mathrm{~ms}$ for upright and upside-down stimuli, respectively). The main effect of Correspondence was significant, $F(1$, 46) $=24.094, p<.001, \eta_{p}^{2}=0.34$, with faster RTs in handle-to-hand corresponding than in non-corresponding trials (377 vs. $385 \mathrm{~ms}$ ). The interaction between Orientation and Correspondence was not significant, $F(1,46)<1$, indicating that the magnitude of the correspondence effect did not differ between the upright and the upside-down orientation groups. For the ERs, the main effect of Correspondence was significant, $F(1,46)=9.078, p=.004, \eta_{p}^{2}=0.16$, with lower percentage of errors in handle-to-hand corresponding than 
in non-corresponding trials ( 2.2 vs. $3.4 \%$ ). Neither the main effect of Orientation, $F(1,46)=2.928, p=.094, \eta_{p}^{2}=0.06$ (upright stimuli $=2.3 \%$, upside-down stimuli $=3.4 \%$ ), nor the Orientation $\times$ Correspondence interaction, $F(1,46)<1$, $p=.865, \eta_{p}^{2}=0.001$, reached significance (see Table 1).

Mean correct reaction times (RTs) for the two experiments were then submitted to ANOVAs with Experiment (Experiment 2A vs. Experiment 2B) as between-subjects variable, and Correspondence (handle-to-hand corresponding vs. non-corresponding trials) as within-subjects variable. As in Experiment 1, we firstly compared responses to upright stimuli of all the participants in Experiment $2 \mathrm{~A}$ to responses of half the participants of Experiment $2 \mathrm{~B}$ who responded to upright stimuli. Secondly, we compared responses to upright stimuli in Experiment 2A to those of the other half the participants of Experiment 2B who responded to upside-down stimuli.

Experiment $2 A$ vs. $2 B$ upright stimuli Mean RTs from Experiment 2A (390 ms) and Experiment 2B (375 ms) did not differ, $F<1, \eta_{p}^{2}=0.02$. The main effect of Correspondence was significant with faster RTs in handle-to-hand corresponding $(381 \mathrm{~ms})$ than in non-corresponding (385 ms) trials, $F(1,46)=6.013, p=.018, \eta_{p}^{2}=0.12$. The interaction between Experiment and Correspondence was also significant, $F(1,46)=4.577, p=.038, \eta_{p}^{2}=0.09$. Paired-sample $t$ tests clarified that there was no significant handle-to-hand correspondence effect in Experiment 2A (390 vs. $390 \mathrm{~ms}$ ), $t(23)=0.203, p=.841, d_{z}=0.04$, whereas a significant handle-to-hand correspondence effect (with upright stimuli) was evident in Experiment 2B (372 vs. $379 \mathrm{~ms}), t(23)=3.602$, $p=.002, d_{z}=0.74,($ Bonferroni-corrected $p$ level $=0.025$ ) (see Table 1; Fig. 4 upper panel). For ERs, the main effects of Correspondence was not significant (2.4 vs. $3.1 \%), F(1$, 46) $=3.946 p=.053, \eta_{p}^{2}=0.08$. The main effect of Experiment (Experiment $2 \mathrm{~A}=2.1 \%$ vs. Experiment $2 \mathrm{~B}=3.4 \%$ ), as well as the Correspondence $\times$ Experiment interaction were not significant, $F(1,46)=3.781, p=.058, \eta_{p}^{2}=0.08$, and $F(1,46)=1.047, p=312, \eta_{p}^{2}=0.02$, respectively (see Table 1; Fig. 4 bottom panel).

Experiment 2A-upright vs. Experiment $2 B$-upside-down stimuli The main effect of Experiment was not significant (Experiment $2 \mathrm{~A}=390 \mathrm{~ms}$ vs. Experiment $2 \mathrm{~B}=386 \mathrm{~ms}$ ), $F<1, \eta_{p}^{2}=0.001$. The main effect of Correspondence was significant with faster RTs in handle-to-hand corresponding (386 $\mathrm{ms})$ than in non-corresponding $(390 \mathrm{~ms})$ trials, $F(1$, $46)=6.145, p=.017, \eta_{p}^{2}=0.12$. The Experiment $\times$ Correspondence interaction was also significant, $F(1,46)=4.777$ $p=.034, \eta_{p}^{2}=0.09$. Paired-sample $t$ tests confirmed that there was a significant handle-to-hand correspondence effect with upside-down stimuli in Experiment 2B (383 vs. $390 \mathrm{~ms}$ ), $t(23)=3.374, p=.003, d_{z}=0.76$ (Bonferronicorrected $p$ level $=0.025$ ) (see Table 1; Fig. 4 upper panel). For ERs, the main effects of Correspondence was significant
$(1.8$ vs. $2.6 \%), F(1,46)=6.380 p=.015, \eta_{p}^{2}=0.12$. The main effect of Experiment was not significant (Experiment $2 \mathrm{~A}=2.1 \%$ vs. Experiment $2 \mathrm{~B}=2.3 \%), F(1,46)<1$, $\eta_{p}^{2}=.001$; the Correspondence $\times$ Experiment interaction was also not significant, $F(1,46)=1.970=0.167, \eta_{p}^{2}=0.04$. (see Table 1; Fig. 4 bottom panel).

Hence, even though in Experiment 2A the response required to the participants was more similar to the action typically performed to interact with a given object, the activation of an affordance for a grasping action was not facilitated. Indeed, a handle-to-hand correspondence effect did not emerge when only one grasp response had to be emitted and there was no other agent in charge of the alternative response. Experiment 2B replicated the results of Experiment $1 \mathrm{~B}$ and added further support to the idea that the handle-to-hand correspondence effect does not depend on the activation of affordances. Rather, it appears to depend on the spatial coding of both stimulus and response sets.

Furthermore, the within-experiment analysis of the joint go/no-go Experiment $2 \mathrm{~B}$ showed no overall difference between responses to upright and upside-down stimuli, as well as no effect on the size of the correspondence effect. This confirms the conclusions provided for previous Experiments $1 \mathrm{~A}$ and $1 \mathrm{~B}$ that the presence of a correspondence effect in the joint task and its absence in the individual one could only be attributed to task differences.

\section{Distribution analyses}

Overall, the absence of a correspondence effect in the individual relative to the joint go/no-go experiments did not fully rule out the possibility that affordances were active in the individual task. Indeed, grasp affordances might have required time to activate, affecting performance at slower RTs only. To test this possibility, distribution analyses of RTs (bin analyses) were run to investigate whether individual go/no-go correspondence effects were present at the slower RTs - a finding that would support the affordance activation account. More in general, these analyses also investigated possible differences in terms of RT distribution between individual and joint go/no-go tasks.

For the individual go/no-go tasks of Experiment $1 \mathrm{~A}$ and 2A, RTs distributions as a function of handle-to-hand correspondence were divided into quintiles (bins), and the mean RT for each quintile was calculated. An ANOVA was run with Experiment (Experiment 1A vs. Experiment 2A) as between-subjects variable, and Bin (from bin1 to bin 5) and Correspondence as within-subject variables.

Considering the way data were grouped, the Bin main effect necessarily turned out to be significant and was neither reported nor discussed. Neither the main effects of Experiment, $F(1,46)<1$ and Correspondence, $F(1,46)<1$, $p=.508, \eta_{p}^{2}=0.01$, nor the Bin $\times$ Correspondence and the 

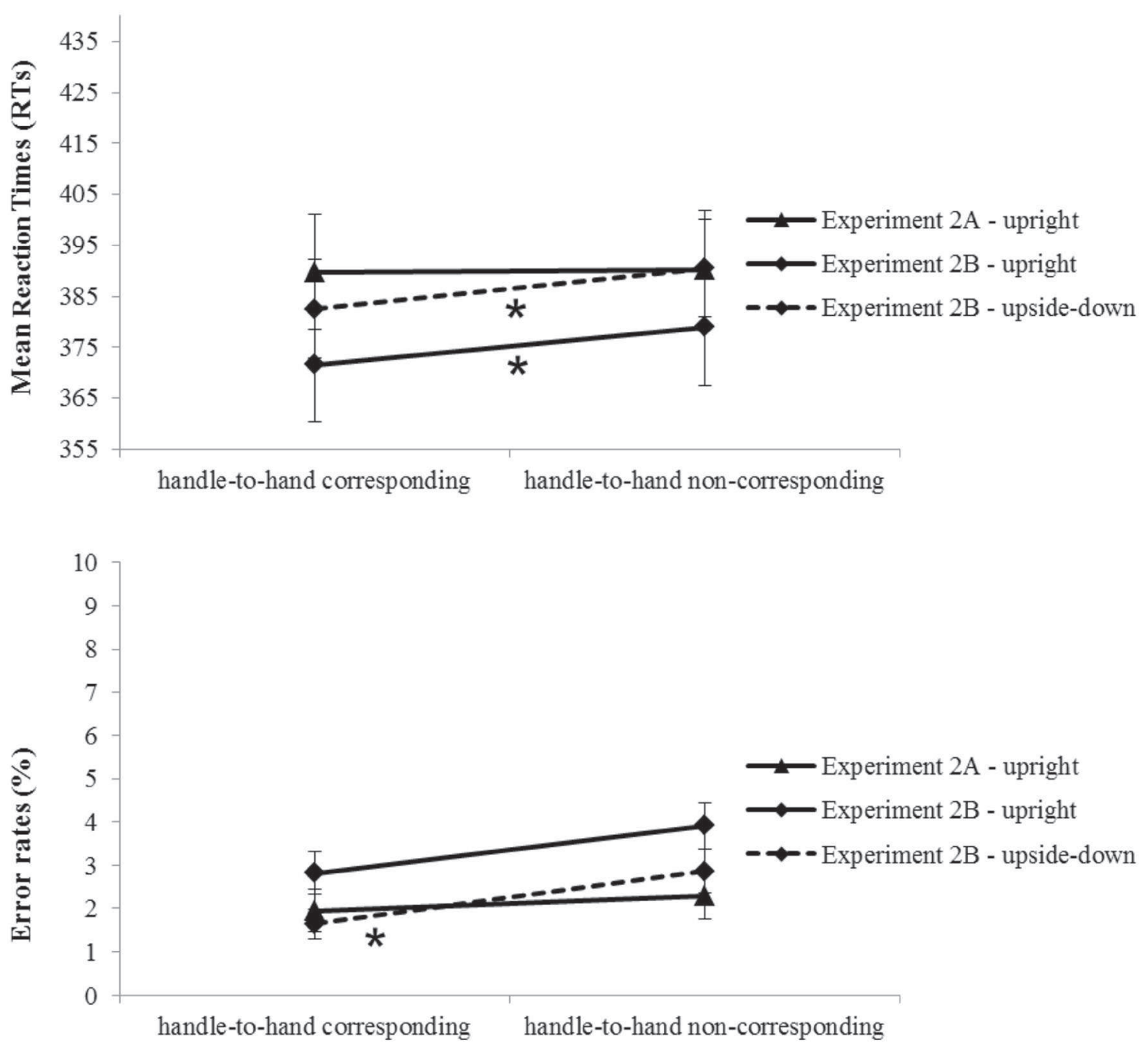

Fig. 4 Mean reaction times (RTs) in milliseconds, and error rates (ERs) in percentage as a function of Correspondence (handle-to-hand corresponding vs. non-corresponding trials) for Experiments 2A and

Bin $\times$ Correspondence $\times$ Experiment interactions, $F$ s $(4$, $184)<1.047, p s<.385, \eta_{p}^{2} \mathrm{~s}<0.02$, reached significance. Thus, when the task was performed by one single participant (go/no-go task), the handle-to-hand correspondence effect was nonsignificant across bins, irrespective of response type (button press or precision grasp) (see Table 2).
2B. Asterisks denote significant differences. Bars represent standard errors of the mean

For the joint go/no-go tasks of Experiment 1B and 2B, RTs distributions as a function of stimulus orientation and handle-to-hand correspondence were divided into quintiles (bins), and mean RT for each quintile was calculated. An ANOVA was run with Experiment (Experiment 1B vs. Experiment 2B) and Orientation (upright vs. upside down)
Table 2 Correspondence effect size (ms) across quintiles (bins) for Experiments $1 \mathrm{~A}$ and $1 \mathrm{~B}$, and for Experiments 2A and 2B

\begin{tabular}{|c|c|c|c|c|c|c|}
\hline \multirow[b]{2}{*}{ Bin } & \multirow{2}{*}{$\begin{array}{l}\text { Experiment 1A } \\
\text { Upright }\end{array}$} & \multicolumn{2}{|c|}{ Experiment 1B } & \multirow{2}{*}{$\begin{array}{l}\text { Experiment 2A } \\
\text { Upright }\end{array}$} & \multicolumn{2}{|c|}{ Experiment $2 \mathrm{~B}$} \\
\hline & & Upright & Upside down & & Upright & Upside down \\
\hline 1 & 4 & 7 & 8 & 4 & 4 & -2 \\
\hline 2 & 1 & 10 & 9 & 1 & 7 & 5 \\
\hline 3 & 0 & 14 & 11 & 0 & 6 & 6 \\
\hline 4 & 1 & 14 & 14 & -1 & 8 & 9 \\
\hline 5 & 3 & 14 & 12 & -2 & 9 & 11 \\
\hline
\end{tabular}


as the between-subjects variables, and Bin (from bin 1 to bin 5) and Correspondence as within-subject variables. The main effect of Experiment was significant, $F(1,92)=8.090$, $p=.005, \eta_{p}^{2}=0.08$, with slower RTs in Experiment $1 \mathrm{~B}$ (405 ms) relative to Experiment 2B (380 ms). The main effect of Orientation was also significant, $F(1,92)=4.930$, $p=.029, \eta_{p}^{2}=0.05$, with faster RTs in the upright (383 ms) relative to the upside-down condition $(402 \mathrm{~ms})$. The two variables did not interact, $F(1,92)=<1, p=.349, \eta_{p}^{2}=0.01$. The main effect of Correspondence was significant, $F(1$, $92)=48.817, p<.001, \eta_{p}^{2}=0.35$ (388 vs. $397 \mathrm{~ms}$ ) and it interacted with Experiment, $F(1,92)=3.977, p=.049$, $\eta_{p}^{2}=.04$. Paired-sample $t$ tests showed that the handleto-handle correspondence effect was significant in both Experiments 1B (399 vs. $411 \mathrm{~ms})$ and 2B (377 vs. $383 \mathrm{~ms}$ ), $t \mathrm{~s}(47)=6.011$ and $3.840, p \mathrm{~s}<.001, d_{z} \mathrm{~s}=0.87$ and 0.55 , with a larger effect in Experiment 1B (12 ms) than in Experiment 2B (6 ms). The Bin variable only interacted with Correspondence, $F(4,368)=6.009, p<.001, \eta_{p}^{2}=.06$. Pairedsamples $t$ tests showed that the correspondence effect was not significant at bin $1(4 \mathrm{~ms}), t(95)=1.983, p=.050$, $d_{z=0.21}$, and significant at bins $2-5(8,9,11$, and $12 \mathrm{~ms})$ $t \mathrm{~s}(95)<6.733, p \mathrm{~s}<0.001, d_{z} \mathrm{~s}>0.63$ (Bonferroni corrected $p$ level $=.01)$. No other interaction reached significance $F_{\mathrm{s}}(4$, 368) < 1 (Fig. 5; Table 2).

The results of these analyses clearly ruled out the possibility that affordances were activated at slower RTs in the individual go/no-go tasks. Indeed, in both Experiments $1 \mathrm{~A}$ and $2 \mathrm{~A}$ the handle-to-hand correspondence effect for upright stimuli was nonsignificant across the bin distribution. In Experiments $1 \mathrm{~B}$ and $2 \mathrm{~B}$, the size of the correspondence effect reached significance early in the RT distribution (bin 2) and remained significant across the distribution for both upright and upside-down stimuli.

Lastly, we also wanted to rule out an alternative explanation of our results: that the significant correspondence effect in the joint conditions and the non-significant effect in the individual conditions simply depended on overall RTs differences between the two tasks (at least between the upright groups). To discard this possibility, we have already showed that overall RTs did not differ between Experiment 1A (392 ms) and Experiment 1B (391 ms), and between Experiment 2A (390 ms) and Experiment 2B (375 ms), $F$ s $<1$. To further address this point, we conducted extra distribution analyses that compared Experiment $1 \mathrm{~A}$ and $1 \mathrm{~B}$, as well as Experiment $2 \mathrm{~A}$ and $2 \mathrm{~B}$, for the upright condition
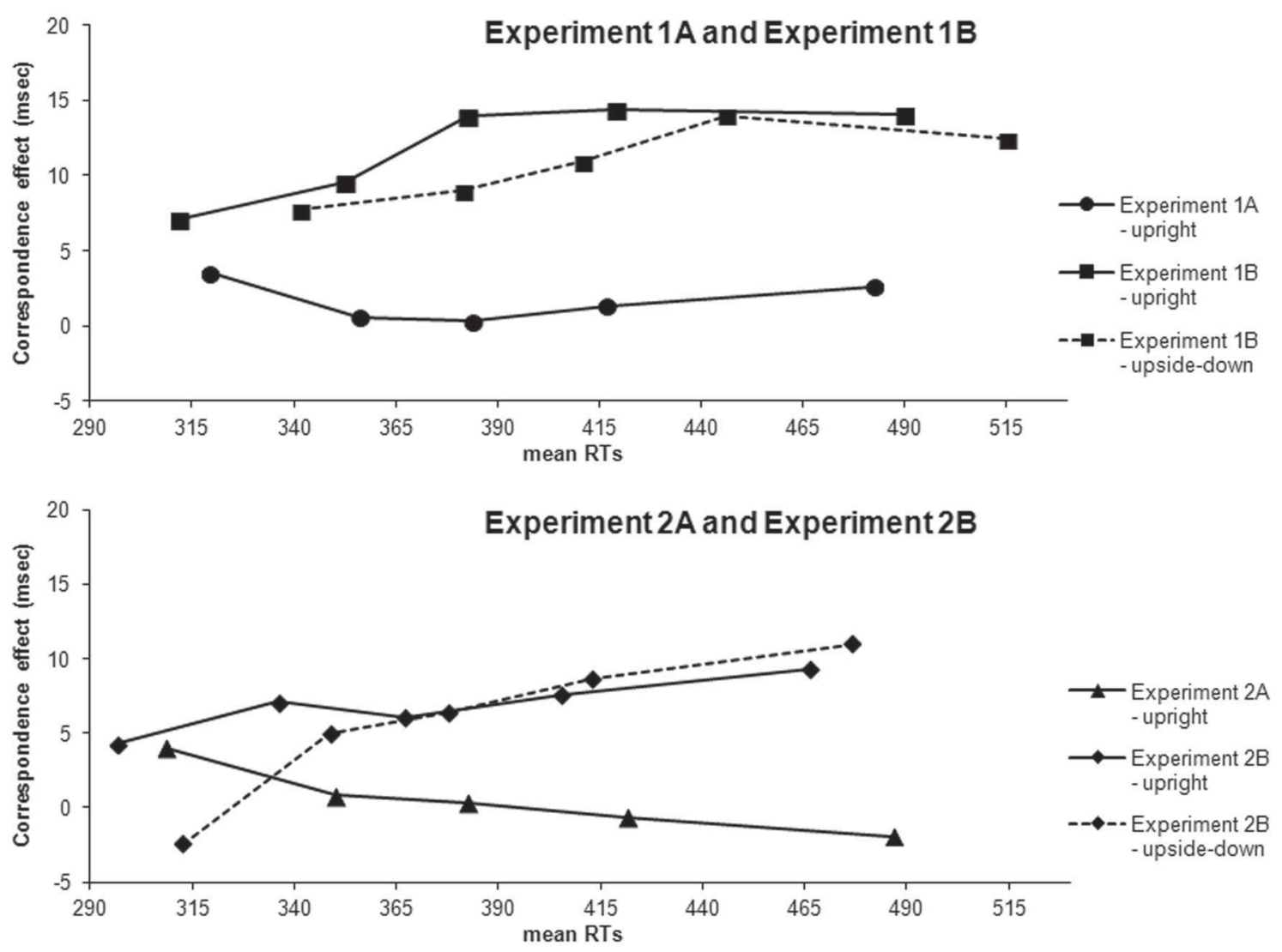

Fig. 5 Distribution analyses of RTs. The size of the correspondence effect (in milliseconds) plotted as a function of the mean RTs for each quintile 
only. In both the analyses, the crucial Experiment $\times$ Correspondence $\times$ Bin interactions were not significant, $F(4$, $184)=2.144, p=.081, \eta_{p}^{2}=0.04$, and $F(4,184)=1.863$, $p=.119, \eta_{p}^{2}=0.04$, respectively. These results indicate that the already described pattern of results (i.e., the significant correspondence effect in the joint tasks, and the nonsignificant effect in the individual tasks) was independent of response speed, that is, was similar at fast and slow RT bins.

\section{Sequential analyses}

To investigate the possible effects of previous handle-tohand correspondence, as well as of previous go/no-go assignments, we conducted trial-to-trial sequential analyses (see Liepelt, Wenke, Fischer, \& Prinz, 2011) in both the individual and joint go/no-go experiments. Responses that were 2 standard deviations below/above each participant's overall mean, incorrect responses in both current and preceding trials, as well as the first trial in each block were excluded from the analyses. Separate ANOVAs were conducted for the individual and joint tasks, and for the joint task for upright and upside-down stimuli. Mean RTs were computed as a function of Transition (go vs. no-go trial in $N-1$ ), Preceding trial correspondence (corresponding vs. non-corresponding), and current trial correspondence (corresponding vs. non-corresponding trial). Since significant and nonsignificant effects of Correspondence in both the joint and in the individual tasks were confirmed, they are not reported.

In Experiment 1A, the main effect of Transition was significant, $F(1,23)=19.735, p<.001, \eta_{p}^{2}=0.46$, with faster RTs in trials preceded by a no-go trial (384 ms) than in trials preceded by a go trial (399 ms). This finding is consistent with the use of no-go trials as a cue for predicting the occurrence of the next go trial, this resulting in better response preparation after no-go trials. Neither Preceding trial correspondence, $F(1,23)=1.059, p=.314, \eta_{p}^{2}=0.04$, nor the interactions involving these factors, $F \mathrm{~s}(1,23)<2.5$, $p \mathrm{~s}>.125, \eta_{p}^{2} \mathrm{~s}<.09$, reached significance.
In Experiment 1B, the effect of Transition was significant for the upright stimuli group, $F(1,23)=5.166, p=.033$, $\eta_{p}^{2}=0.18\left(\mathrm{go}_{N-1}=393 \mathrm{~ms}\right.$ vs. no-go $\left.{ }_{N-1}=387 \mathrm{~ms}\right)$, whereas the upside-down stimuli group showed a nonsignificant effect, even though in the same direction, $F(1,23)=4.136$, $p=.054, \eta_{p}^{2}=0.15\left(\mathrm{go}_{N-1}=422 \mathrm{~ms}\right.$ vs. no- $\left.\mathrm{go}_{N-1}=416 \mathrm{~ms}\right)$. Similarly to Experiment $1 \mathrm{~A}$, stimulus repetition or switch was probably used to predict whether it was one's own or the other participant's turn in responding (Liepelt et al., 2011; Liepelt, Wenke, \& Fischer, 2013), with better response preparation following the response of the other participant. No other source of significance was observed for upright, $F_{\mathrm{s}}(1$, $23)<1.3, p \mathrm{~s}>0.274, \eta_{p}^{2} \mathrm{~s}<0.05$, and for upside down, $F \mathrm{~s}(1$, 23) $<3.8, p s>0.063, \eta_{p}^{2} \mathrm{~s}<0.14$, stimuli.

In Experiment 2A, neither the main effect of Preceding trial correspondence, $F(1,23)=1.052, p=.316, \eta_{\mathrm{p}}^{2}=.04$ and Transition, $F(1,23)=0.304, p=.587, \eta_{p}^{2}=.01$, nor the interactions involving the two factors, $F_{\mathrm{s}}(1,23)<1.3$, $p s>0.256, \eta_{p}^{2} s<0.06$, reached significance.

In Experiment $2 \mathrm{~B}$, the upside-down stimuli group displayed a significant Transition $\times$ Current trial correspondence interaction, $F(1,23)=5.805, p=.024, \eta_{p}^{2}=.20$, with a significant correspondence effect in trials preceded by a go trial (382 vs. $393 \mathrm{~ms}$ ), $t(23)=3.971, p=.001, d_{z}=0.90$, but not in trials preceded by a no-go trial (382 vs. $386 \mathrm{~ms}$ ), $t(23)=1.603, p=.123, d_{z}=0.33$. Furthermore, a significant Transition $\times$ Preceding trial correspondence $\times$ Current trial correspondence interaction was observed for both the upright, $F(1,23)=6.352, p=.019, \eta_{\mathrm{p}}^{2}=.22$, and the upsidedown stimuli groups, $F(1,23)=5.229, p=.032, \eta_{\mathrm{p}}^{2}=.18$. In both the groups, the correspondence effect was significant in trials preceded by a go corresponding trial, $t \mathrm{~s}(23)<4.1$, $p \mathrm{~s}<0.004, d_{z} \mathrm{~s}>0.65$, but not in trials preceded by a go noncorresponding trial, $t \mathrm{~s}(23)<1.4, p \mathrm{~s}>0.186, d_{z} \mathrm{~s}>0.18$. Furthermore, the correspondence effect was not significant in trials preceded by a no-go corresponding trial, $t \mathrm{~s}(23)<0.4$, $p \mathrm{~s}>0.681, d_{z} \mathrm{~s}>0.03$, and in trials preceded by a no-go non-corresponding trial, $t \mathrm{~s}(23)<2.5, p \mathrm{~s}>0.023, d_{z} \mathrm{~s}>0.38$ (corrected $p$ level $=0.01$ ). No other sources of significance were found, $F \mathrm{~s}(1,23)<1.5$ (see Table 3 ).
Table 3 Mean RTs for corresponding $(C)$, noncorresponding (NC) trials and correspondence effect preceded by go/nogo and corresponding $\left(C_{N-1}\right)$ /non-corresponding $\left(\mathrm{NC}_{N-1}\right)$ trials for Experiments $1 \mathrm{~A}$ and $1 \mathrm{~B}$, and for Experiments $2 \mathrm{~A}$ and $2 \mathrm{~B}$

\begin{tabular}{|c|c|c|c|c|c|c|c|c|c|c|c|c|}
\hline & \multicolumn{6}{|c|}{ Go/Go } & \multicolumn{6}{|c|}{ Nogo/Go } \\
\hline & \multicolumn{3}{|c|}{$C_{N-1}$} & \multicolumn{3}{|c|}{$\mathrm{NC}_{N-1}$} & \multicolumn{3}{|c|}{$C_{N-1}$} & \multicolumn{3}{|c|}{$\mathrm{NC}_{N-1}$} \\
\hline & $C$ & $\mathrm{NC}$ & Effect & $C$ & $\mathrm{NC}$ & Effect & $C$ & $\mathrm{NC}$ & Effect & $C$ & $\mathrm{NC}$ & Effect \\
\hline Experiment $1 \mathrm{~A}$-upright & 395 & 403 & 8 & 398 & 398 & 0 & 385 & 385 & 0 & 384 & 382 & -2 \\
\hline Experiment 1B-upright & 385 & 398 & 13 & 388 & 401 & 12 & 382 & 392 & 10 & 382 & 392 & 10 \\
\hline Experiment $1 \mathrm{~B}$-upside down & 417 & 430 & 13 & 418 & 423 & 5 & 407 & 421 & 14 & 413 & 422 & 9 \\
\hline Experiment $2 \mathrm{~A}$ - upright & 388 & 390 & 2 & 393 & 392 & -1 & 389 & 387 & -2 & 387 & 391 & 4 \\
\hline Experiment $2 \mathrm{~B}$ - upright & 372 & 386 & $14 *$ & 374 & 377 & 4 & 372 & 373 & 1 & 367 & 377 & 9 \\
\hline Experiment $2 \mathrm{~B}$ - upside down & 379 & 397 & $18 *$ & 384 & 390 & 6 & 383 & 385 & 2 & 380 & 388 & 8 \\
\hline
\end{tabular}


To summarize, sequential effects due to prior trial nature and prior trial correspondence were observed only in Experiment $2 \mathrm{~B}$ with both upright and upside-down stimuli. Specifically, the handle-to-hand correspondence effect was significant when the responding participant within the pair also responded in the preceding trial and this response spatially corresponded to the position of the stimulus's handle, whereas it did not reach significance when the participant responded to the preceding non-corresponding trial, and when she/he did not respond in the preceding trials. These results are in line with previous findings in individual twochoice tasks showing a decreased or absent Simon effect following non-corresponding than corresponding trials (Akçay \& Hazeltine, 2007; Hommel, Proctor, \& Vu, 2004; Iani, Rubichi, Gherri, \& Nicoletti, 2009; Iani, Stella, \& Rubichi, 2014). They are also consistent with results observed in joint go/no-go tasks reporting a negative Simon effect following non-corresponding trials (Liepelt et al., 2011).

Even though participants performed a joint task, sequential effects were not observed in Experiment 1B. This difference between experiments could be due to stronger bottom-up driven S-R feature bindings (Hommel, 1998) in Experiment 2B as compared to Experiment $1 \mathrm{~B}$ because in Experiment 2B response locations were closer to stimulus locations relative to Experiment 1B.

Sequential analyses of Experiments $1 \mathrm{~A}$ and $2 \mathrm{~A}$ showed no handle-to-hand correspondence effect irrespective of whether the preceding trial was a go or a no-go trial, and of whether it was corresponding or non-corresponding. This last result differs from the sequential effects reported by Liepelt et al. (2011) for an individual go/no-go task. However, it was obtained with different stimulus materials. Indeed in our study, centrally presented pictures of real objects were employed, whereas in Liepelt et al. (2011) lateralized shape stimuli were used. The nature of the spatial codes produced for object stimuli (Pellicano et al., 2017b; Cho \& Proctor, 2010) is thought to be different from that of lateralized shape or color stimuli (Baroni, Pellicano, Lugli, Nicoletti, \& Proctor, 2012); therefore it might be the case that differences in low-level feature binding mechanisms applied to our stimulus set.

In conclusion, the observed sequential effects seem to be more consistent with the view that basic interactions between stimulus and response codes (Simon-like effect), instead of activation of motor affordances, were the basis of our results.

\section{General discussion}

The handle-to-hand correspondence effect refers to the finding of faster and more accurate responses when the responding hand is aligned with the graspable part of an object tool, compared to when they lay on opposite sides. The present study was aimed at investigating whether this effect depends on the activation of grasping affordances (affordance activation account) or rather it is due to spatial coding of stimuli and responses, and to their dimensional overlap (location coding account).

According to the affordance activation account, handleto-hand corresponding responses are faster and more accurate than noncorresponding ones because they best fit with the motor affordance elicited by the object (i.e., a grasping action of the hand aligned with the handle). However, according to the location coding account, the effect depends on the automatic activation of a generic, grasp-unrelated spatial response that is on the same side of the stimulus. Crucially, this automatic response is only activated when there is dimensional overlap between the stimulus spatial code and the response spatial code. Indeed, the location coding account considers the handle-to-hand correspondence effect as a Simon effect for which the spatial value of the stimuli depends on the orientation of their visually salient portion, which correspond to their graspable tips (as they provide asymmetry to the object stimuli).

We tested the assumption that, if the identification of an object brings to the activation of the motor programs that subtend its manipulation (i.e., its proper grasping affordances), the handle-to-hand correspondence effect should emerge irrespective of whether the task requires the emission of a single response (individual go/no-go task), or of two responses (joint go/no-go task). To test this assumption we introduced two manipulations. First, we manipulated the availability of response alternatives by employing unimanual (single effector) go/no-go tasks performed by single participants (i.e., absence of spatial response alternative, Experiment $1 \mathrm{~A}$ and $2 \mathrm{~A}$ ), and by pairs of participants (i.e., two spatial response alternatives, Experiment $1 \mathrm{~B}$ and $2 \mathrm{~B}$ ). Indeed, our study utilized the availability of response alternatives, as well as their absence, to discriminate between the affordance activation account and the location coding account. Second, we employed different response modes: a buttonpress response in Experiments $1 \mathrm{~A}$ and $1 \mathrm{~B}$, as for most of previous investigations on handle-to-hand correspondence effect (see Proctor \& Miles, 2014), and a precision grasp action in Experiments 2A and 2B. This response type was introduced to increase the possibility that motor affordances could be evoked (Bub \& Masson, 2010; Bub et al., 2018; Couth, Gowen, \& Poliakoff, 2014; Iani et al., 2011).

We found no handle-to-hand correspondence effect in the individual go/no-go version of the task either when a buttonpress response (Experiment 1A) or a grasping (Experiment $2 \mathrm{~A})$ response was required. A significant handle-to-hand correspondence effect, however, emerged when the task was performed by pairs of participants sitting alongside each other (Experiments 1B and 2B). Taken together, these results 
do not support the idea that motor affordances are automatically activated for meaningful objects: unimanual responses did not benefit from these activations even if handle-to-hand alignment and non-alignment conditions were provided for the employed single effector. This negative evidence was made stronger by the results of Experiment 2A showing that even when the required response was more similar to the grasping gesture to be afforded by the handle orientation, no sign of an affordance effect was observed. Distribution analyses of RTs displayed that the correspondence effect in Experiment $1 \mathrm{~A}$ and $2 \mathrm{~A}$ stayed nonsignificant across the whole RTs distribution, thus ruling out the possibility that full activation of affordances was slower and needed more time to be observed. To note, the size and the time course of the handle-to-hand correspondence effect observed in the joint go/no-go Experiment 1B and 2B were similar to those observed in individual choice-reaction experiments that employed the same stimulus materials (Riggio et al., 2008). This suggests, in light of the most recent investigations (see Pellicano et al., 2017b), that similar stimulus-response coding mechanisms took place in the present joint go/no-go experiments relative to previous individual choice-reaction ones. Furthermore, trial-to-trial sequential analyses for Experiments $1 \mathrm{~A}$ and $2 \mathrm{~A}$ showed no significant correspondence effect depending on previous trial correspondence and previous go/nogo requirements, thus suggesting that motor affordances were never activated in our go-nogo conditions employing centrally presented object stimuli (but see Liepelt et al., 2011 for significant sequential effects with lateralized shape stimuli).

These results are also relevant in light of four features of our experiments supposed to favor the activation of motor affordances (see Borghi \& Riggio, 2015; Pappas, 2014). First, in individual go/no-go experiments, upright object stimuli were matched to go trials, as upright, canonical orientation is more plausible to facilitate the activation of grasping affordances compared to upside-down orientation (Riddoch, et al., 1998; Rounis \& Humphreys, 2015). Second, it has been shown that the activation of affordances depends on the amount of realistic visual information consistent with what is encountered in the natural environment. More precisely, affordance effects have been found when detailed photographs of objects were employed but not when 2D silhouettes of the same stimuli were presented (Pappas, 2014). Third, previous studies have shown that the activation of affordances depends on the task. Indeed, affordance effects have been shown only when the task required deep processing of the object characteristics (e.g., shape processing), while they were absent if superficial processing (e.g., color processing) was required (Tipper, Paul, \& Hayes, 2006; Pellicano et al., 2010b). Fourth, it has been displayed that the activation of affordances is modulated by the context. Indeed, affordances are only activated when object stimuli are located in the near peripersonal, but not in the far extrapersonal space (Costantini et al., 2010).

Consistent with these findings, our four experiments employed ecologically valid pictures of kitchen objects, implemented a vertical-orientation discrimination task for which a deeper processing was required and displayed the stimuli within the peripersonal space. The second and fourth point were even more relevant for Experiments $2 \mathrm{~A}$ and $2 \mathrm{~B}$ in which the hand mimicking the grasping gesture was held a few centimeters close to the realistic object picture. Notwithstanding these manipulations, no evidence supporting the affordance activation account was found.

Rather, our results are consistent with the more parsimonious location coding account that considers the handleto-hand correspondence effect as a Simon-like effect (Cho $\&$ Proctor, 2010). Indeed, the results of the present study suggest that asymmetries in the structure of our stimuli generated spatial codes which overlapped with the spatial codes formed in the joint go/no-go tasks to discriminate between the two response alternatives (emitted by the two participants). This is consistent with the response discrimination account of the Simon effect (Ansorge \& Wühr, 2004) and with one of the most recent accounts of the joint Simon effect, that is, the referential coding account (Dolk et al., 2013 ; 2014). Because of this dimensional overlap, the spatial orientation of the handle (i.e., the visually salient tip of the object) automatically activated corresponding, grasping-unrelated responses that facilitated and interfered with performance in handle-to-hand corresponding and noncorresponding trials, respectively. This generated a Simon-like effect similar to the one previously observed with other stimuli conveying spatial information when centrally presented, as for example: pointing arrows (e.g., Iani, Ricci, Baroni, \& Rubichi, 2009; Masaki, Takasawa, \& Yamazaki, 2000; Pellicano, Lugli, Baroni \& Nicoletti, 2009; Ricciardelli, Bonfiglioli, Iani, Rubichi, \& Nicoletti, 2007), spatial words (e.g., Pellicano et al., 2009) or gazing eyes (e.g., Ricciardelli et al., 2007; Ristic \& Kingstone, 2006).

Crucially and consistent with previous studies, when only one response had to be emitted (individual go/no-go tasks), there was no need to spatially code it, and ultimately no Simon-like effect was observed (Dolk et al., 2013; 2014; Prinz, 2015; Dolk \& Prinz, 2016).

In conclusion, the present study provided further support to the location coding account of the handle-to-hand correspondence effect through an approach based on availability of response alternatives. Beyond the manipulations reported above, future studies should investigate further aspects supposed to increase the chances for affordance activations; namely: the nature of the stimuli (real objects) combined with appropriate real actions (grasp, or reach-and-grasp actions). 
Funding A.P. was supported by the START Programme der Medizinischen Fakultät der RWTH-Aachen (START Projekt 691240, 144/12). C.I. was supported by a grant from the University of Modena and Reggio Emilia, Fondo di Ateneo per la Ricerca (FAR2014).

\section{Compliance with ethical standards}

Conflict of interest A. P. declares that he has no conflict of interest. L. L. declares that she has no conflict of interest. F. B. declares that he has no conflict of interest. S. R. declares that he has no conflict of interest. C. I. declares that she has no conflict of interest. R. N. declares that he has no conflict of interest.

Ethical approval All procedures performed in studies involving human participants were in accordance with the ethical standards of the institutional and/or national research committee and with the 1964 Helsinki Declaration and its later amendments or comparable ethical standards.

Informed consent Informed consent was obtained from all individual participants included in the study.

\section{References}

Akçay, Ç, \& Hazeltine, E. (2007). Conflict monitoring and feature overlap: Two sources of sequential modulations. Psychonomic Bulletin \& Review, 14, 742-748.

Alluisi, E. A., \& Warm, J. S. (1990). Things that go together: A review of stimulus-response compatibility and related effects. In R. W. Proctor \& T. G. Reeve (Eds.), Stimulus response compatibility: An integrated perspective (pp. 3-30). Amsterdam: North Holland.

Ansorge, U., \& Wühr, P. (2004). A response-discrimination account of the Simon effect. Journal of Experimental Psychology: Human Perception and Performance, 30, 365-377. https://doi. org/10.1037/0096-1523.30.2.365.

Baroni, G., Pellicano, A., Lugli, L., Nicoletti, R., \& Proctor, R. W. (2012). Influence of Temporal Overlap on Time Course of the Simon Effect. Experimental Psychology, 59, 88-98.

Berlucchi, G., Crea, F., Di Stefano, M., \& Tassinari, G. (1977). Influence of spatial stimulus-response compatibility on reaction time of ipsilateral and contralateral hand to lateralized light stimuli. Journal of Experimental Psychology: Human Perception and Performance, 3, 505-517.

Borghi, A. M., \& Riggio, L. (2015). Stable and variable affordances are both automatic and flexible. Frontiers in Human Neuroscience, 9, 351. https://doi.org/10.3389/fnhum.2015.00351.

Bub, D. B., \& Masson, M. E. J. (2010). Grasping beer mugs: On the dynamics of alignment effects induced by handled objects. Journal of Experimental Psychology: Human Perception and Performance, 36, 341-358. https://doi.org/10.1037/a0017606.

Bub, D. B., Masson, M. E. J., \& Kumar, R. (2018). Time Course of Motor Affordances Evoked by Pictured Objects and Words. Journal of Experimental Psychology: Human Perception and Performance, 44, 53-68. https://doi.org/10.1037/xhp0000431.

Buccino, G., Sato, M., Cattaneo, L., Rodà, F., \& Riggio, L. (2009). Broken affordances, broken objects: a TMS study. Neuropsychologia, 47, 3074-3078. https://doi.org/10.1016/j.neuropsychologi a.2009.07.003.

Cho, D. T., \& Proctor, R. W. (2013). Object-based correspondence effects for action-relevant and surface-property judgments with keypress responses: Evidence for a basis in spatial coding. Psychological Research Psychologische Forschung, 77, 618-636. https://doi.org/10.1007/s00426-012-0458-4.
Cho, D. T., \& Proctor, R. W. (2010). The object-based Simon effect: Grasping affordance or relative location of the graspable part? Journal of Experimental Psychology: Human Perception and Performance, 36, 853-861. https://doi.org/10.1037/a0019328.

Cho, D. T., \& Proctor, R. W. (2011). Correspondence effects for objects with opposing left and right protrusions. Journal of Experimental Psychology: Human Perception and Performance, 37, 737-749. https://doi.org/10.1037/a0021934.

Ciardo, F., Lugli, L., Nicoletti, R., Rubichi, S., \& Iani, C. (2016). Action-space coding in social contexts. Scientific Reports, 6, 22673. https://doi.org/10.1038/srep22673.

Costantini, M., Ambrosini, E., Tieri, G., Sinigaglia, C., \& Committeri, G. (2010). Where does an object trigger an action? An investigation about affordances in space. Experimental Brain Research, 207, 95-103. https://doi.org/10.1007/s00221-010-2435-8.

Couth, S., Gowen, E., \& Poliakoff, E. (2014). Dissociating affordance and spatial compatibility effects using a pantomimed reaching action. Experimental Brain Research, 232, 855-864. https://doi. org/10.1007/s00221-013-3798-4.

De Stefani, E., Innocenti, A., De Marco, D., Busiello, M., Ferri, F., Costantini, M., \& Gentilucci, M. (2014). The spatial alignment effect in near and far space: a kinematic study. Experimental Brain Research, 232, 2431-2438. https://doi.org/10.1007/s0022 1-014-3943-8.

Dittrich, K., Dolk, T., Rothe-Wulf, A., Klauer, K. C., \& Prinz, W. (2013). Keys and seats: Spatial response coding underlying the joint Simon effect. Attention, Perception, \& Psychophysics, 75, 1725-1736. https://doi.org/10.3758/s13414-013-0524-z.

Dittrich, K., Rothe, A., \& Klauer, K. C. (2012). Increased spatial salience in the social Simon task: A response coding account of spatial compatibility effects. Attention Perception and Psychophysics, 74, 911-929. https://doi.org/10.3758/s13414-012-0304-1.

Dolk, T., Hommel, B., Colzato, L. S., Schütz-Bosbach, S., Prinz, W., \& Liepelt, R. (2014). The Joint Simon Effect: A review and theoretical integration. Frontiers in Psychology, 5, 974.

Dolk, T., Hommel, B., Prinz, W., \& Liepelt, R. (2013). The (not so) Social Simon effect: a referential coding account. Journal of Experimental Psychology: Human Perception and Performance, 39, 1248-1260. https://doi.org/10.1037/a0031031.

Dolk, T., \& Prinz, W. (2016). What it takes to share a task: Sharing versus shaping task representations. In S. S. Obhi \& E. S. Cross (Eds.), Shared representations: Sensorimotor foundations of social life (pp. 3-21). Cambridge: Cambridge University Press.

Fagioli, S., Hommel, B., \& Schubotz, R. I. (2007). Intentional control of attention: Action planning primes action-related stimulus dimensions. Psychological Research Psychologische Forschung, $71,22-29$.

Ferraro, L., Iani, C., Mariani, M., Milanese, N., \& Rubichi, S. (2011). Facilitation and interference components in the joint Simon effect. Experimental Brain Research, 211(3-4), 337-343.

Ferraro, L., Iani, C., Mariani, M., Nicoletti, R., Gallese, V., \& Rubichi, S. (2012). Look what I am doing: Does observational learning take place in evocative task-sharing situations? PLoS One, 7(8), e43311. https://doi.org/10.1371/journal.pone.0043311.

Goslin, J., Dixon, T., Fischer, M. H., Cangelosi, A., \& Ellis, R. (2012). Electrophysiological examination of embodiment in vision and action. Psychological Science, 23, 152-157. https://doi. org/10.1177/0956797611429578.

Hommel, B. (1996). S-R compatibility effects without response uncertainty. Quarterly Journal of Experimental Psychology, 49A, 546571. https://doi.org/10.1080/713755643.

Hommel, B. (1998). Event files: Evidence for automatic integration of stimulus-response episodes. Visual Cognition, 5, 183-216.

Hommel, B., Proctor, R. W., \& Vu, K.-P. L. (2004). A feature integration account of sequential effects in the Simon task. Psychological Research Psychologische Forschung, 68, 1-17. 
Iani, C., Baroni, G., Pellicano, A., \& Nicoletti, R. (2011). On the relationship between Affordance and Simon effects: Are the effects really independent? Journal of Cognitive Psychology, 23, 121131. https://doi.org/10.1080/20445911.2011.467251.

Iani, C., Ricci, F., Baroni, G., \& Rubichi, S. (2009). Attention control and susceptibility to hypnosis. Consciousness and Cognition, 18, 856-863. https://doi.org/10.1016/j.concog.2009.07.002.

Iani, C., Rubichi, S., Gherri, E., \& Nicoletti, R. (2009). Co-occurrence of sequential and practice effects in the Simon task: Evidence for two independent mechanisms affecting response selection. Memory \& Cognition, 37, 358-367. https://doi.org/10.3758/ MC.37.3.358.

Iani, C., Stella, G., \& Rubichi, S. (2014). Response inhibition and adaptations to response conflict in 6- to 8-year-old children: Evidence from the Simon effect. Attention, Perception, \& Psychophysics, 76, 1234-1241. https://doi.org/10.3758/s13414-014-0656-9.

Iani, C., Ferraro, L., Maiorana, N.V., Gallese, V., \& Rubichi, S. (2018). Do already grasped objects activate motor affordances? Psychological Research. https://doi.org/10.1007/s00426-018-1004-9

Kornblum, S., Hasbroucq, T., \& Osman, A. (1990). Dimensional overlap: Cognitive basis for stimulus-response compatibility-A model and taxonomy. Psychological Review, 97, 253-270. https ://doi.org/10.1037/0033-295X.97.2.253.

Lien, M.-C., Gray, D., Jardin, E., \& Proctor, R. W. (2014). Correspondence effects are primarily modulated by object location not grasping affordance: An event-related potentials study. Journal of Cognitive Psychology, 26,, 679-698. https://doi.org/10.1080/20445 911.2014.940959.

Lien, M.-C., Jardin, E., \& Proctor, R. (2013). An electrophysiological study of the object-based correspondence effect: Is the effect triggered by the intended grasping action? Attention, Perception and Psychophysics, 75, 1862-1882. https://doi.org/10.3758/s1341 4-013-0523-0.

Liepelt, R., Wenke, D., \& Fischer, R. (2013). Effects of feature integration in a hands-crossed version of the Social Simon paradigm. Psychological Research Psychologische Forschung, 77, 240-248.

Liepelt, R., Wenke, D., Fischer, R., \& Prinz, W. (2011). Trial-to-trial sequential dependencies in a social and non-social Simon task. Psychological Research Psychologische Forschung, 75, 366-375.

Lu, C.-H., \& Proctor, R. W. (1995). The influence of irrelevant location information on performance: A review of the Simon and spatial Stroop effects. Psychonomic Bulletin and Review, 2, 174-207. https://doi.org/10.3758/BF03210959.

Lugli, L., Iani, C., Milanese, N., Sebanz, N., \& Rubichi, S. (2015). Spatial parameters at the basis of social transfer of learning. Journal of Experimental Psychology: Human Perception and Performance, 41(3), 840-849. https://doi.org/10.1037/xhp0000047.

Lugli, L., Iani, C., Nicoletti, R., \& Rubichi, S. (2013). Emergence of the go/no-go Simon effect by means of practice and mixing paradigms. Acta Psychologica, 144, 19-24. https://doi.org/10.1016/j. actpsy.2013.04.021.

Masaki, H., Takasawa, N., \& Yamazaki, K. (2000). An electrophysiological study of the locus of the interference effect in a stimulusresponse compatibility paradigm. Psychophysiology, 37, 464-472. https://doi.org/10.1111/1469-8986.3740464.

Masson, M. E., Bub, D. N., \& Breuer, A. T. (2011). Priming of reach and grasp actions by handled objects. Journal of Experimental Psychology: Human, Perception and Performance, 37, 14701484. https://doi.org/10.1037/a0023509.

Milanese, N., Iani, C., \& Rubichi, S. (2010). Shared learning shapes human performance: Transfer effects in task sharing. Cognition, 116, 15-22. https://doi.org/10.1016/j.cognition.2010.03.010.

Ottoboni, G., Iani, C., Tessari, A., \& Rubichi, S. (2013). Modulation of the affordance effect through transfer of learning. Quarterly Journal of Experimental Psychology, 66, 2295-2302. https://doi. org/10.1080/17470218.2013.863370.
Pappas, Z. (2014). Dissociating Simon and affordance compatibility effects: silhouettes and photographs. Cognition, 133, 716-728. https://doi.org/10.1016/j.cognition.2014.08.018.

Pavese, A., \& Buxbaum, L. (2002). Action matters: The role of action plans and object affordances in selection for action. Visual Cognition, 9, 559-590. https://doi.org/10.1080/13506 280143000584.

Pellicano, A., Borghi, A. M., \& Binkofski, F. (2017a). Editorial: Bridging the theories of affordances and limb apraxia. Frontiers in Human Neuroscience, 11, 148. https://doi.org/10.3389/fnhum .2017.00148.

Pellicano, A., Iani, C., Borghi, A. M., Rubichi, S., \& Nicoletti, R. (2010b). Simon-like and functional affordance effects with tools: the effects of object perceptual discrimination and object action state. Quarterly Journal of Experimental Psychology, 63, 2190-2201. https://doi.org/10.1080/17470218.2010.486903.

Pellicano, A., Iani, C., Rubichi, S., Ricciardelli, P., Borghi, A. M., \& Nicoletti, R. (2010a). Real life motor training modifies spatial performance: The advantage of being drummers. American Journal of Psychology, 123, 169-179. https://doi.org/10.5406/ amerjpsyc.123.2.0169.

Pellicano, A., Koch, I., \& Binkofski, F. (2017b). Location-Coding Account Versus Affordance-Activation Account in Handle-toHand Correspondence Effects: Evidence of Simon-Like Effects Based on the Coding of Action Direction. Journal of Experimental Psychology: Human Perception and Performance, 43, 1647-1666. https://doi.org/10.1037/xhp0000414.

Pellicano, A., Lugli, L., Baroni, G., \& Nicoletti, R. (2009). The Simon effect with conventional signals. A time-course analysis. Experimental Psychology, 56, 219-227. https://doi. org/10.1027/1618-3169.56.4.219.

Pellicano, A., Thill, S., Ziemke, T., \& Binkofski, F. (2011). Affordances, adaptive tool use and grounded cognition. Frontiers in Psychology, 2, 53. https://doi.org/10.3389/fpsyg.2011.00053.

Prinz, W. (2015). Task representation in individual and joint settings. Frontiers in Human Neuroscience, 9, 268. https://doi. org/10.3389/fnhum.2015.00268.

Proctor, R. W., \& Miles, J. D. (2014). Does the concept of affordance add anything to explanations of stimulus-response compatibility effects? In B. H. Ross (Ed.), The psychology of learning and motivation (Vol. 60, pp. 227-266). San Diego: Academic Press.

Proctor, R. W., \& Vu, K.-P. L. (2006). Stimulus-response compatibility principles: Data, theory and application. Boca Raton: CRC Press.

Ricciardelli, P., Bonfiglioli, C., Iani, C., Rubichi, S., \& Nicoletti, R. (2007). Spatial coding and central patterns: Is there something special about the eyes? Canadian Journal of Experimental Psychology, 61, 79-90. https://doi.org/10.1037/cep2007_2_79.

Riddoch, J. M., Edwards, M. G., Humphreys, G. W., West, R., \& Heafield, T. (1998). Visual affordances direct action: neuropsychological evidence from manual interference. Cognitive Neuropsychology, 15, 645-683. https://doi.org/10.1080/026432998381041.

Riggio, L., Iani, C., Gherri, E., Benatti, F., Rubichi, S., \& Nicoletti, R. (2008). The role of attention in the occurrence of the affordance effect. Acta Psychologica, 127, 449-458. https://doi.org/10.1016/j. actpsy.2007.08.008.

Ristic, J., \& Kingstone, A. (2006). Attention to arrows: Pointing to a new direction. Quarterly Journal of Experimental Psychology, 59, 1921-1930. https://doi.org/10.1080/17470210500416367.

Roest, S. A., Pecher, D., Naeije, L., \& Zeelenberg, R. (2016). Alignment effects in beer mugs: Automatic action activation or response competition? Attention Perception and Psychophysics, 78(6), 1665-1680.

Rounis, E., \& Humphreys, G. (2015). Limb apraxia and the "affordance competition hypothesis". Frontiers in Human Neuroscience, 9, 429. https://doi.org/10.3389/fnhum.2015.00429 
Sebanz, N., Bekkering, H., \& Knoblich, G. (2006). Joint actions: bodies and minds moving together. Trends in Cognitive Science, 10, 70-76. https://doi.org/10.1016/j.tics.2005. 12.009.

Sebanz, N., \& Knoblich, G. (2009). Prediction in joint action: what, when, and where. Topics in Cognitive Science, 1, 353-367. https ://doi.org/10.1111/j.1756-8765.2009.01024.x.

Sebanz, N., Knoblich, G., \& Prinz, W. (2003). Representing others' actions: Just like one's own? Cognition, 88, B11-B21. https://doi. org/10.1016/S0010-0277(03)00043-X.

Sebanz, N., Knoblich, G., \& Prinz, W. (2005). How to share a task: Co-representing stimulus-response mappings. Journal of Experimental Psychology: Human Perception and Performance, 31, 1234-1246. https://doi.org/10.1037/0096-1523.31.6.1234.

Simon, J. R. (1990). The effects of an irrelevant directional cue on human information processing. In R. W. Proctor \& T. G. Reeve (Eds.), Stimulus-response compatibility. An integrated perspective (pp. 31-86). Amsterdam: Elsevier.

Song, X., Chen, J., \& Proctor, R. W. (2014). Correspondence effects with torches: Grasping affordance or visual feature asymmetry? Quarterly Journal of Experimental Psychology, 67, 665-675. https://doi.org/10.1080/17470218.2013.824996.
Tipper, S. P., Paul, M. A., \& Hayes, A. E. (2006). Vision for action: the effects of object property discrimination and action state on affordance compatibility effects. Psychonomic Bulletin and Review, 13, 493-498. https://doi.org/10.3758/BF03193875.

Tucker, M., \& Ellis, R. (1998). On the relations between seen objects and components of potential actions. Journal of Experimental Psychology: Human Perception and Performance, 24, 830-846. https://doi.org/10.1037/0096-1523.24.3.830.

Tucker, M., \& Ellis, R. (2001). The potentiation of grasp types during visual object categorization. Visual Cognition, 8, 769-800. https ://doi.org/10.1080/13506280042000144.

Wühr, P., \& Ansorge, U. (2007). A Simon effect in memory retrieval: Evidence for the response discrimination account. Psychonomic Bulletin and Review, 14, 984-988.

Wühr, P., Biebl, R., \& Ansorge, U. (2008). The impact of stimulus and response variability on S-R correspondence effects. Journal of Experimental Psychology: Learning, Memory and Cognition, 34, 533-545. https://doi.org/10.1037/0278-7393.34.3.533. 